\title{
Exploration risk evaluation using object-based modeling, an example from the Tertiary fractured play, western Qaidam Basin of China
}

\author{
Chen Zhuoheng ${ }^{*}$, Hu Suyun ${ }^{2}$, Jin Zhijun ${ }^{3}$, Pang Xiongqi ${ }^{3}$, Jiang Zhenxue ${ }^{3}$ \\ and Osadetz G. Kirk ${ }^{1}$ \\ ${ }^{1}$ Geological Survey of Canada, Calgary, AB T2L 2A7, Canada \\ ${ }^{2}$ Research Institute of Petroleum Exploration \& Development, PetroChina, Beijing 100083, China \\ ${ }^{3}$ School of Resources and Information Technology, China University of Petroleum, Beijing 102249, China
}

\begin{abstract}
Geological risk evaluation reveals the uncertainty of converting an anticipated resource potential in an identified exploration target into an economic petroleum accumulation prior to drilling. Providing consistent and unbiased estimates of geological risk for all exploration targets in an area of interest is essential in risk evaluation. This paper discusses the potential use of an object-based stochastic procedure for geological risk evaluation at the play level. The object-based model of SuperSD, as a data integration tool, can integrate geological information of petroleum system elements that control occurrences of petroleum pools with the spatial correlation characteristics of the discoveries in a play. Other information, such as the estimated total play potential and size characteristics, from conventional resource assessments can be also incorporated into the model as geological constraints. The uncertainty associated with the data and domain knowledge in the predicted pool locations is expressed as a probability map, representing the geological exploration risk of the play. By incorporating all available information and checking the consistency of models with geological constraints, the object-based model improves predictions of petroleum occurrences, thus enhancing the associated risk evaluation. The proposed method was applied to the fractured petroleum play of the western Qaidam Basin in northwestern China in order to illustrate the use of the object-based method for risk evaluation.
\end{abstract}

Key words: Exploration risk mapping, stochastic simulation, Qaidam Basin

\section{Introduction}

The goal of geological risk analysis seeks to determine to what degree of certainty a potential drilling target either productive or nonproductive may be, on the basis of our understanding of the domain knowledge and available data. In other words, we wish to know prior to drilling what is the chance of turning a potential target into a commercial discovery. The common practice of geological risk analysis starts with a play analysis, which examines all essential geological elements necessary for oil and gas accumulation in a region (White, 1988; 1993) and subsequently assign probability values to each essential geological element. The probability of exploration success is the product of the probabilities of all the essential geological elements for petroleum accumulation in that prospect (White, 1988; Snow et al, 1997; Otis and Schneidermann, 1997; Rose, 2001). There are several drawbacks in this type of geological risk evaluation. First, there are substantial subjective judgments

*Corresponding author. email: zchen@NRCan.gc.ca Received April 21, 2008 involved in the probability assignments. In the assignments, favorable levels are judged by the assessors using geological analogs for all geological elements, and each favorable level corresponds to a range of probability values. The resulting risk estimates depend on the preferences of the assigned assessors. As a consequence of the subjective judgments, risk evaluation result may not be consistent and repeatable. For example, if independent assessments were conducted by different people, the probability values of the risk could vary significantly. In the process of exploration decision, a consistent and repeatable risk evaluation result is more desirable. The current practice may also not be easy to incorporate spatial correlation among the prospects. Petroleum accumulation at a specific location is not an isolated event but one of many accumulations produced by the same geological processes in a petroleum system. A better understanding of spatial variation of the objects and their spatial relationship to the presence of essential geological elements are important for geological risk analysis.

With improvement of computer handling of geographical information and the availability of spatial statistical tools, attempts have been made to evaluate geological risk by taking spatial characteristics of exploration targets into consideration 
in recent years. Chen et al $(2000 ; 2001 ; 2002 ; 2004)$ and Hood et al (2000) have proposed various techniques for characterizing spatial variability of geological conditions and estimating probability of petroleum accumulation at play level. For example, treating risk estimation as two group classifications in a multivariate space, Chen and Osadetz (2006a) were able to use multivariate and Bayesian approach for geological risk mapping. While the uncertainty associated with the classification represents the geological risk of a prospect being "dry", the "diagnostic criteria" that can be used to distinguish between these two groups are indicators of geological processes and geological variables characterizing conditions necessary for formation of petroleum accumulations. The resulting probability map of petroleum occurrence depicts the spatial variation of geological conditions for petroleum accumulation. This provides a consistent basis for risk analysis and target ranking, as well as exploration planning. With the application of a model-based stochastic simulation in petroleum resource assessment, geological risk evaluation can also be conducted by estimating the uncertainty in prediction of the occurrence of undiscovered petroleum accumulations (Chen and Osadetz, 2006b). Both methods are successfully applied to Nanpu Sag of Bohai Bay Basin, China (Hu et al, 2007; Chen et al, 2008).

Gao et al (2000) proposed an object-based stochastic simulation for estimating the petroleum potential in a play, providing not only a tool for predicting the geographical locations of undiscovered petroleum accumulations, but most importantly providing a tool for data integration. A particular use of this type of tool is geological risk evaluation. In this paper, we present a systematic procedure for geological risk analysis using the object-based model at petroleum play level. The fractured petroleum play in western Qaidam Basin of China was used as an application example to illustrate the principles of the method and procedure of evaluating geological risk. The data in this study are compiled by PetroChina for its national petroleum resource assessment in 2001. The data also include assessment results of conventional petroleum resources in the play.

\section{Methodology descriptions}

Gao et al (2000) proposed an object-based stochastic model that simulates the likely locations of undiscovered petroleum accumulations by simultaneously considering essential petroleum system elements that control the formation of petroleum occurrences and the spatial correlation among petroleum accumulations in a study area. In the object-based model, pool accumulation objects are described by their central locations, volumetric properties and other geological characteristics. All the properties associated with the object are parameterized as a vector (a marked-point) that describes the pool characteristics.

Two types of pools are considered in an exploration play: discovered and undiscovered, forming a pool combination. Suppose that there are $N$ pools in a play, among which $n$ pools are discovered. Let $u_{i}$ be a marked-point associated with the $i^{\text {th }}$ pool $(i=1,2, \ldots, N)$. Accordingly, all $N$ pools, or the pool combination, in the play can be parameterized with a matrix variable:

$$
u=\left(u_{1}, u_{2}, \ldots, u_{N}\right)
$$

There are infinite pool combinations because of uncertainties in the number of undiscovered pools. Intuitively, the prediction of undiscovered pools (e.g., location and size) requires an appropriate pool combination that is consistent with all available information; whereas statistically, one seeks to construct a stochastic model that generates undiscovered pools so that the corresponding pool combination is consistent with available observations and interpretations.

To formulate a stochastic model that incorporates these observations and interpretations, the following generalizations are made:

Hypothesis A. The locations of undiscovered petroleum pools are subject to the petroleum-bearing favorability map or probability map of petroleum occurrence, $f_{B L}(\cdot)$. This means that the likely locations of undiscovered oil and gas accumulations must meet all the necessary geological conditions.

Hypothesis B. Pool properties are subject to a specific statistical model, $f_{B P}(\cdot)$. This statistical model can be inferred from either the characteristics of discovered pools/fields or from compiled information from play analogues.

Hypothesis $\boldsymbol{C}$. Within a petroleum field, pools may show clustering characteristics, while paired pools from different fields are assumed to be independent of each other.

Hypothesis D. The property of anisotropy of clustered pool groups can be described by an average azimuth angle and an average anisotropy ratio.

The simulated pool combinations must be consistent with available data. The following constraints are introduced into the model:

Constraint A. Predicted geological properties at simulated pool locations should be consistent with mapped geological characteristics at those locations.

Constraint B. A simulated pool must be outside the exclusion domain that is determined by dry wells and discovered pools.

Constraint $\boldsymbol{C}$. Pool spacing has some basic constraints, such as the minimum and maximum distances between two pools.

Constraint D. All the simulated pools are located in the most favorable regions of the play not yet occupied by discovered pools.

Constraint $\boldsymbol{E}$. All the pool sizes are assumed to follow a specific probability distribution within a play.

In the stochastic simulation model, the pool spatial distribution is described by the following probability density function (Gao et al, 2000):

$$
\pi(u) \propto f_{B}(u) f_{I}(u) I_{e}(u \mid c) I_{g}(u \mid c) I_{m}(u \mid c)
$$

where

$$
f_{B}(u)=\prod_{i=1}^{N} f_{B L}\left(u_{1 i}\right) f_{B P}\left(u_{2 i}\right), f_{I}(u)=\prod_{1 \leq i<j \leq N} f_{I P}\left(\left|u_{1 i}-u_{1 j}\right|\right),
$$




$$
f_{I P}(d)=\left\{\begin{array}{lc}
\beta_{1} & d \leq b_{1} \\
a_{1}+a_{2} d & b_{1}<d \leq b_{2} \\
1 & b_{2}<d \leq b_{3} \\
a_{3}-a_{4} d & b_{3}<d \leq b_{4} \\
\beta_{2} & b_{4}<d \leq b_{5} \\
a_{5}-a_{6} d & b_{5}<d \leq b_{6} \\
1 & d>b_{6}
\end{array}\right.
$$

in which $\beta_{1}, \beta_{2}, b_{1}, b_{2}, b_{3}, b_{4}, b_{5}$ and $b_{6}$ are parameters associated with the characteristics of inter-object dependencies, and $\left|u_{1 i}-u_{1 j}\right|$ is the Euclidean distance between the centers of pools $u_{i}$ and $u_{j}$. $\beta_{1}$ and $\beta_{2}$ are attractive and repulsive parameters with values between 0 and 1 . Parameters $a_{i}(i=1, \ldots, 6)$ can be determined simply based on the values of $\beta_{1}, \beta_{2}, b_{1}, b_{2}, b_{3}, b_{4}, b_{5}$ and $b_{6}$ according to the continuity of function $f_{I P}(\cdot)$ (Eq. (3)). Fig. 1 is a diagram showing what Eq. (3) may look like. Other functions $f_{B}(u), f_{I}(u), I_{e}(u \mid c)$, $I_{g}(u \mid c)$ and $I_{m}(u \mid c)$ are explained in turn below.

In Eq. (2), function $f_{B}(u)$ represents the individual pool distribution characteristics; whereas $f_{I}(u)$ represents the pairwise inter-relationships between two pools, in which $f_{I}(u)$ depends only on the distances between all pool pairs. Each individual pool is assumed to follow the same distribution function $f_{B L}(\cdot) f_{B P}(\cdot)$. In the distribution function, $f_{B L}(\cdot)$ depends only on the location components $u_{1 i}$ of pool $u_{i}$, and function $f_{B P}(\cdot)$ depends only on the pool property components $u_{2 i}$ that is assumed to follow a multivariate lognormal distribution in this study. The lognormal model of pool property components has been used widely in petroleum resource assessment (Arps and Robert, 1958; Kaufman et al, 1975; Lee and Wang, 1985; Baker et al, 1984; Davis and Chang, 1989). A petroleumbearing favorability map is used to represent the distribution function $f_{B L}(\cdot)$ which indicates the sampling probability of an individual pool location in the simulation. The functions $I_{g}(u \mid c), I_{e}(u \mid c)$ and $I_{m}(u \mid c)$ are indicators, corresponding to constraints A, B and C, respectively. Hypotheses A and B are described by function $f_{B}(u)$. Function $f_{I}(u)$ corresponds to hypotheses $\mathrm{C}$ and $\mathrm{D}$.

When performing the simulation, the independence chain of the Hastings algorithm (Gao and Galli, 1998; Gao et al, 2000 ) is used to generate an appropriate structure for pool combinations in a play. An objective function, that measures the distance between characteristics of realization and desired constraints, is constructed from both the pool size distribution and an entropy maximum criterion. By maximizing the entropy, all simulated undiscovered pools are placed in their most favorable locations. An advantage of the independence chain algorithm is that all the accepted pool combination numerical models are mutually and totally independent. The independence criterion ensures the reasonableness of using these pool combination models as a sample to infer the spatial distribution of undiscovered petroleum resources.

Hundreds and thousands of pool combination numerical models may be generated in a single simulation run, each of which represents an equally-probable pool combination honoring the same assumed statistical features, the same set of constraints and observations, but each of which appears

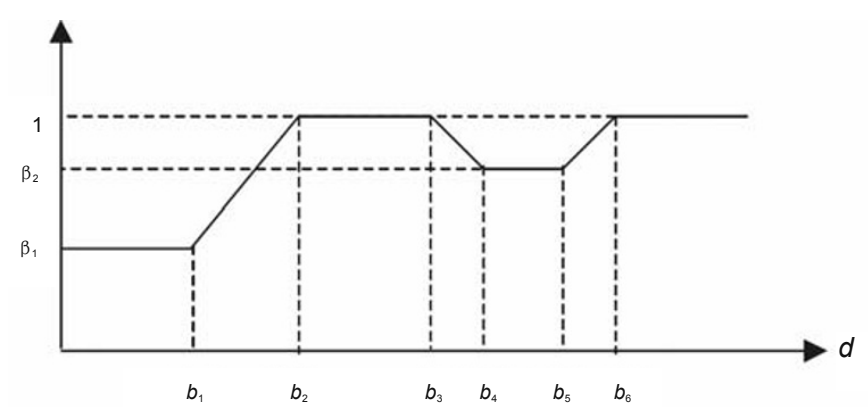

Fig. 1 A step function characterizing the inter-object relationship (pool, filed, accumulation zone) in a play

different from the other pool combinations. There are great uncertainties associated with predicted locations. Therefore, a relative probability map is produced from the numerous combinations generated by a simulation run to characterize the possible locations and associated uncertainties of the prediction. The relative probability map is calculated by counting the number of simulated petroleum occurrences at each cell of a grid divided by the maximum occurrence number among the cells.

Input parameters for the object-based simulation include the size and locations of the discovered oil and gas pools, dry well locations, estimated play resource potential, and a probability density function characterizing the spatial distribution of the undiscovered pools in the study area. For the mathematical details of the model and the proposed algorithms, the reader is referred to Gao et al (2000). A C++ program has been developed by the Geological Survey of Canada (GSC) for the purpose of predicting undiscovered pool locations (Osadetz et al, 2003). Chen et al (2004) presented an application example of the object-based model to petroleum resource assessment of the western Sverdrup Basin of the Canadian Arctic region.

\section{Application to Tertiary fractured play of western Qaidam Basin}

\subsection{Geological setting and data}

The Qaidam Basin (Fig. 2), in the northeastern portion of the Qinghai Tibetan Plateau between the Kunlun and Qilian Mountains, is a composite basin with sedimentary infill of over $14 \mathrm{~km}$, aging from Jurassic to Tertiary. The Jurassic strata of the foreland basin are overlain by Cenozoic stratigraphic successions deposited in lacustrine and fluvial settings of an extensional basin. The Cenozoic extension started with rifting during the latest Cretaceous. The extension setting continued to the Oligocene, and was followed by a tectonic inversion, evidenced by contraction down-warping and reverse faulting (Fig. 3). Previous exploration has been focused on two play types, clastic structural play and fractured play in the Tertiary in the western Qaidam Basin. Up to year 2002, 22 fields and 34 oil and gas pools have been found, contributing a large part of production from this basin (Fig. 3). The object-based method has been applied to the two plays. However, this paper focuses on application to the fractured play.

The reservoirs of this play are fractured limestone, shaly 


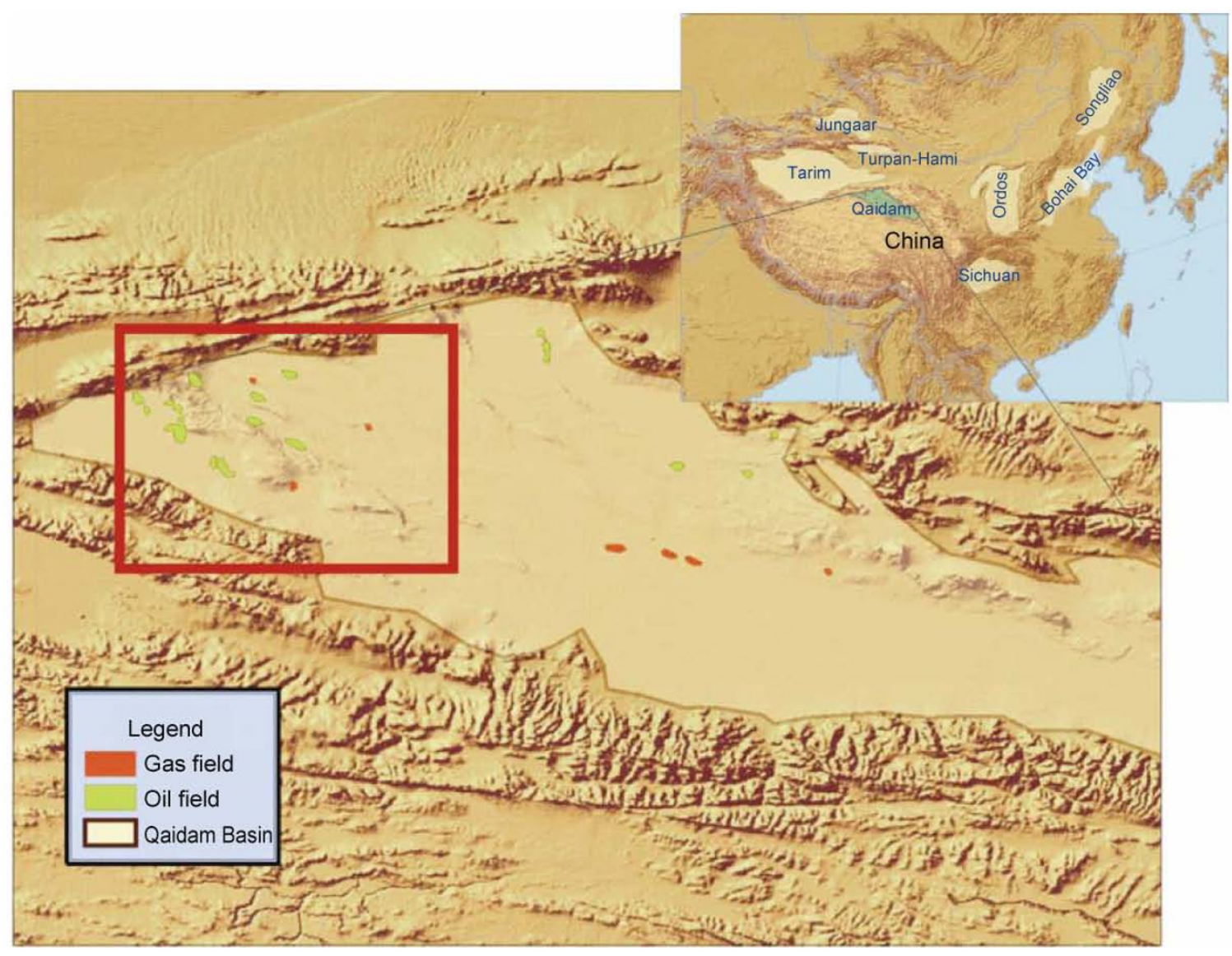

Fig. 2 Location map showing the location of the Qaidam Basin and the study area (red square). Thirty four oil and gas pools are found in the Tertiary successions of western Qaidam Basin

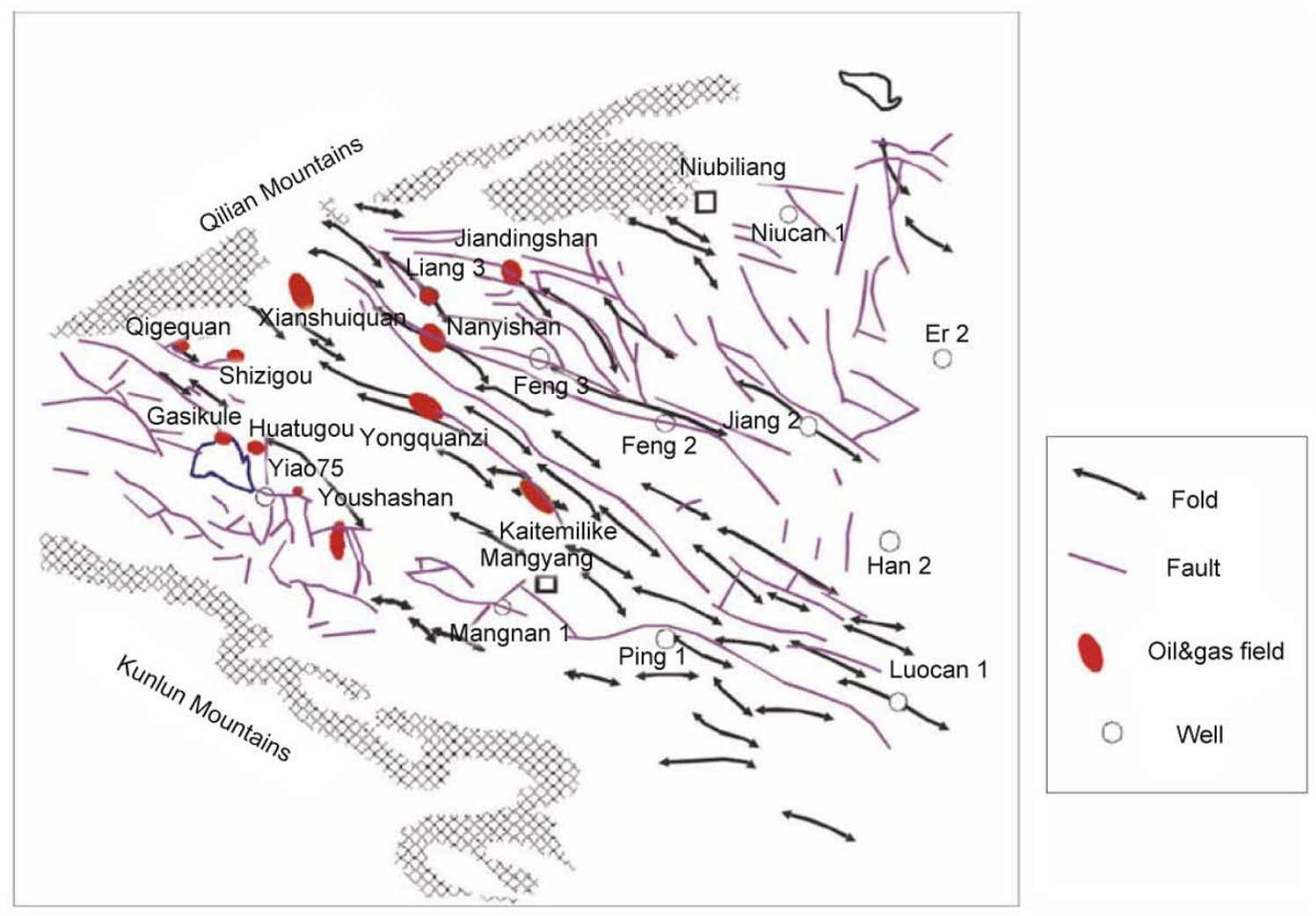

Fig. 3 Regional structure map of the western Qaidam Basin showing the structure style and the major fault/fold zones. Oil and gas discoveries of the fractured play are displayed on the map, indicating the tectonic control on petroleum occurrences 
limestone and shaly sandstone. Vuggy porosity is common in the reservoir. Fractures are believed to be the results of tectonic inversion in the Late Tertiary, and vugs are likely the results of dissolution related to groundwater flow. The presence of the fracture network provides space for oil and gas accumulation and the pathway for fluid flow, thus improving the reservoir by forming secondary porosity (Zhao et al 2004). Primary oil source rocks were a thick sequence of Paleocene-Oligocene deposits in the major rifted depression, and the restricted drainage graben of the rifted protobasin. Recent studies (Hanson et al, 2001; Jin et al, 2002) indicate that the lower Tertiary source rocks with total organic carbon levels (TOCs) $>1.0 \%$ were deposited in hypersaline conditions in the Mangya Depression and entered oil windows in the western Qaidam Basin. All the discoveries in the fractured play are associated with structures, such as anticlines, faulted anticlines, or fault blocks. Fig. 4 is a tectonic intensity index map generated by using fault density and fold intensity based on a structural map (Fig. 3) at the top of the reservoir level from exploration data, illustrating the relationship between petroleum discoveries and tectonic intensity in the fractured play.

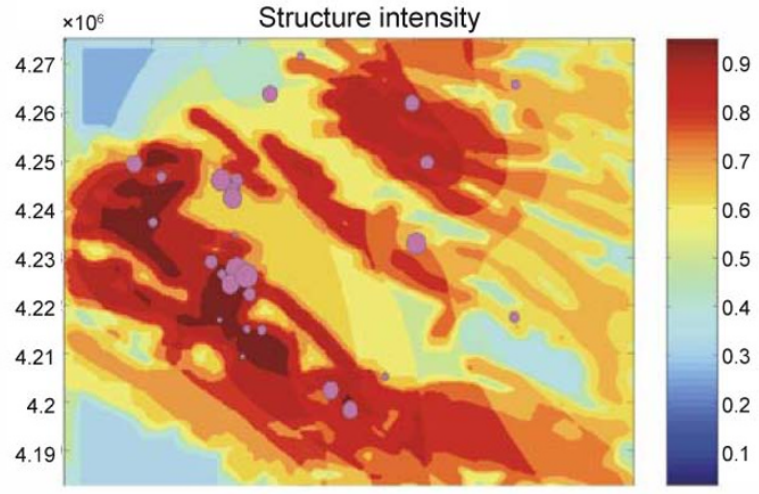

Fig. 4 Structure intensity map derived from fault density and fold intensity of the reservoir intervals. Oil and gas discoveries of the play are overlapped on the map showing the relationship between tectonic intensity and petroleum occurrence

\subsection{Data analysis and results}

\subsubsection{Spatial distribution density function}

The object-based simulation requires a spatial probability density map to allocate the undiscovered accumulations. We know that a pool exists only if all the prerequisite geological conditions for the formation of a petroleum accumulation are present at a specific location. This general knowledge can, in principle, eliminate all locations where the necessary conditions are not met. Unfortunately, available information is often insufficient and it only allows the construction of perception maps, such as geological favorability maps that reflect the interpretation of available data (Chen et al, 2000; $2001 ; 2002)$. The geological favorability map is thus used to approximate the density map. This type of map is only indicative and its quality relies on the quality and quantity of information available as well as the method with which the map was constructed.

An analysis of essential petroleum system elements indicates that the tectonics, location and generation potential of the source rocks and secondary porosities are the most important factors controlling the formation of economic accumulations in the fractured play. A data integration with exploration results using a fuzzy logic algorithm produced a geological favorability map (Fig. 5) that approximated the spatial density function of oil and gas accumulations. It appears that the structure intensity is one of the most important factors for fracture development and represents one of the essential geological elements integrated by using the fuzzy method for the geological favorability mapping. The method with respect to the fuzzy integration and its application to geological favorability mapping are reported by Chen et al (2002).

\subsubsection{Statistical model of field size distribution}

Past experience indicates that the aggregate properties of petroleum accumulations, such as the pool size, pool area, average net pay, and porosity may follow a lognormal distribution. The lognormal model has been used widely in conventional resource assessment (Arps and Robert, 1958; Kaufman et al, 1975; Lee and Wang, 1985; Baker et al, 1984; Davis and Chang, 1989; Chen et al, 1994). Data analysis of the two major reservoir volumetric variables indicates approximation of lognormal distribution (Fig. 6). The sizes of discovered oil and gas pools in the Tertiary fractured play in the western Qaidam Basin fit well with a lognormal distribution (Fig. 7). However, analysis of the discovery sequence found that the sizes of the discovered oil and gas pools had an impact on the order of discovery, thus the estimated lognormal parameters were biased and could not represent the underlying parent population in the play. In this case a multivariate discovery process model, developed by Lee et al (1999) was used to estimate the parameters for the underlying parent lognormal model.

\subsubsection{Inter-object relationships}

Petroleum accumulations are individual objects with welldefined boundaries that often exhibit some spatial features in an area (Barton and Scholz, 1995; La Pointe, 1995; Chen et al, 2001; 2002). Studies elsewhere show that petroleum accumulations may not occur in a random fashion, but in some spatial clustering pattern (Harbaugh et al, 1995). For example, a field could be a natural aggregate of several pools with separate water/oil contacts and different pressure regimes, occurring in a geographic area with restricted areal extent. There may be several trends (plays) in a basin and several petroleum-bearing basins in a continent. Fig. 7 is a variogram showing the spatial correlation among the discoveries. It appears that pools are correlated when they are less than $5 \mathrm{~km}$ apart. The low value in the variogram between $10-20 \mathrm{~km}$ may indicate the clustering at field level. It appears that a correlation exists between discovered fields when the distances are less than $25 \mathrm{~km}$. At distance over 25 $\mathrm{km}$, the occurrence of petroleum accumulations appears to be random. In reality, discovered oil and gas fields in the Qaidam Basin are located in four parallel fold zones. The multi-mode distribution of the inter-field distances may 

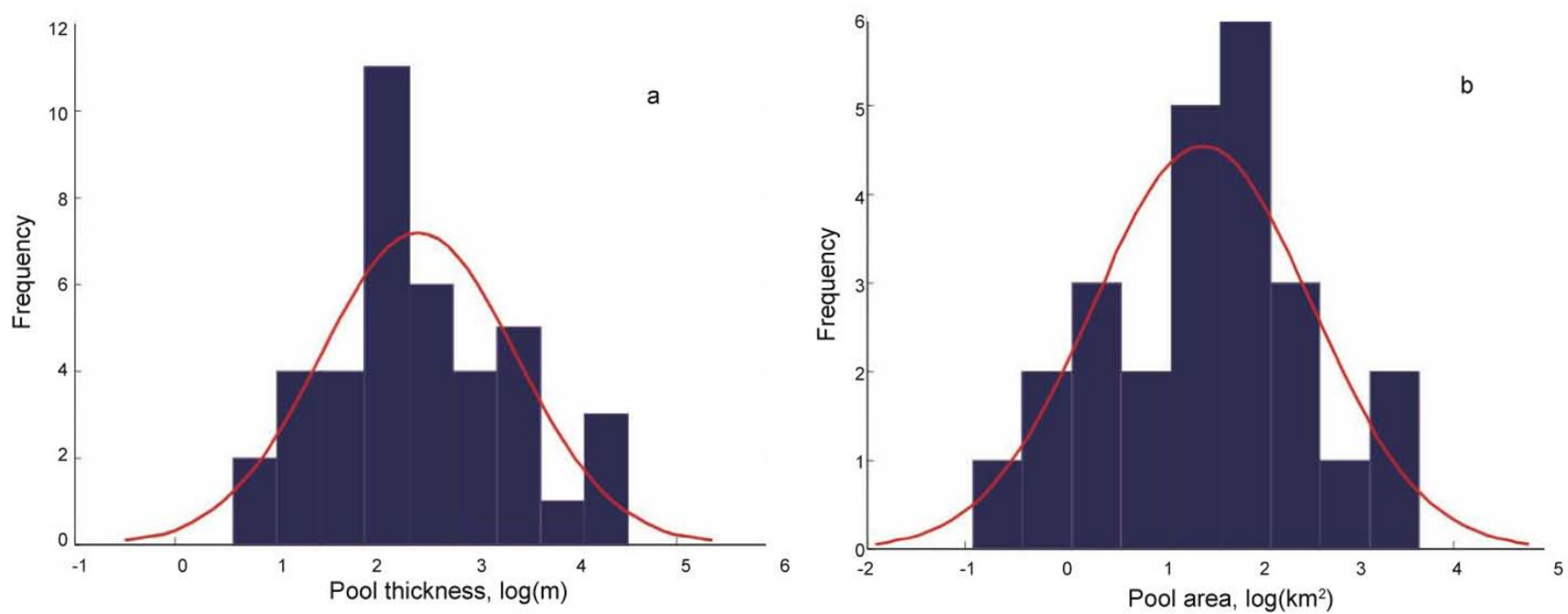

Fig. 5 Histograms and fitted lognormal models for the net-pay (left) and pool area (right) from the discovered oil and gas pools in the fractured play, western Qaidam Basin. These two lognormal distributions provide volumetric constraints for the size distribution in simulating the undiscovered oil and gas pools in the object-based modeling (Hypothesis B)

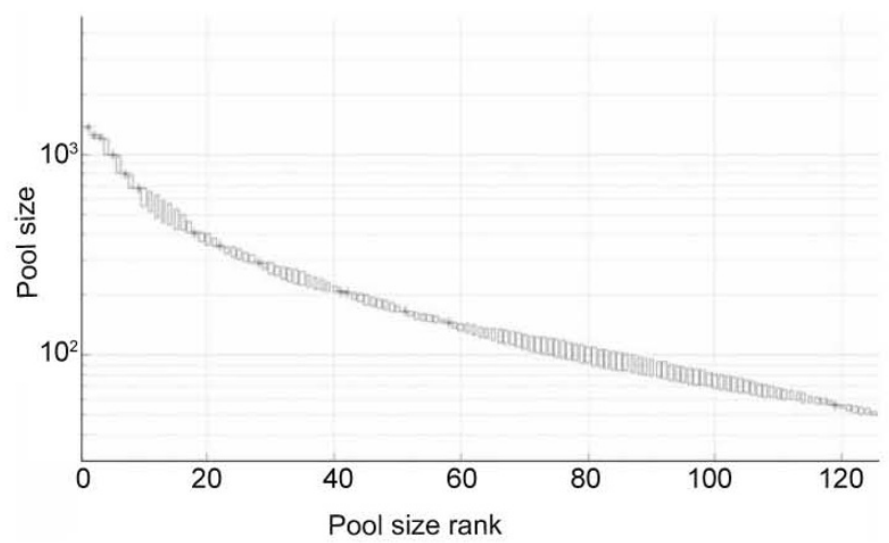

Fig. 6 Pool size by rank plot of the fractured reservoir play derived from the application of the lognormal discovery process model of the Geological Survey of Canada. The discovered pools are marked by stars and the predicted pools to be found are shown by the empty boxes. The boxes indicate the uncertainty range (10-90\% confidence interval). The predicted undiscovered pools are used as constraints in the modeling (Constraint E)

indicate a clustering feature of petroleum accumulations. The distribution of calculated distances of all pools in the play, showing a mode at about $20 \mathrm{~km}$, also supports this inference. The average distance between two adjacent fold zones is about $15 \mathrm{~km}$. A stepwise function was fitted to the experimental variogram for characterizing pool clustering at pool, field and play levels and for the inferences of parameters $b_{i}$. The inferred parameter $b_{i}$ is shown in Fig. 7. The repulsive factor $\beta$, describes the inter-dependencies among fields in each field cluster. The larger the $\beta_{1}$ is, the less the restriction would be on accepting a minimum distance of fields less than the defined distance $b_{1}$. When $\beta_{1}$ is 0 , there is no accepted combination with two fields having a distance greater than $b_{1}$. If $\beta_{1}$ is set at 1 , it means that the predefined

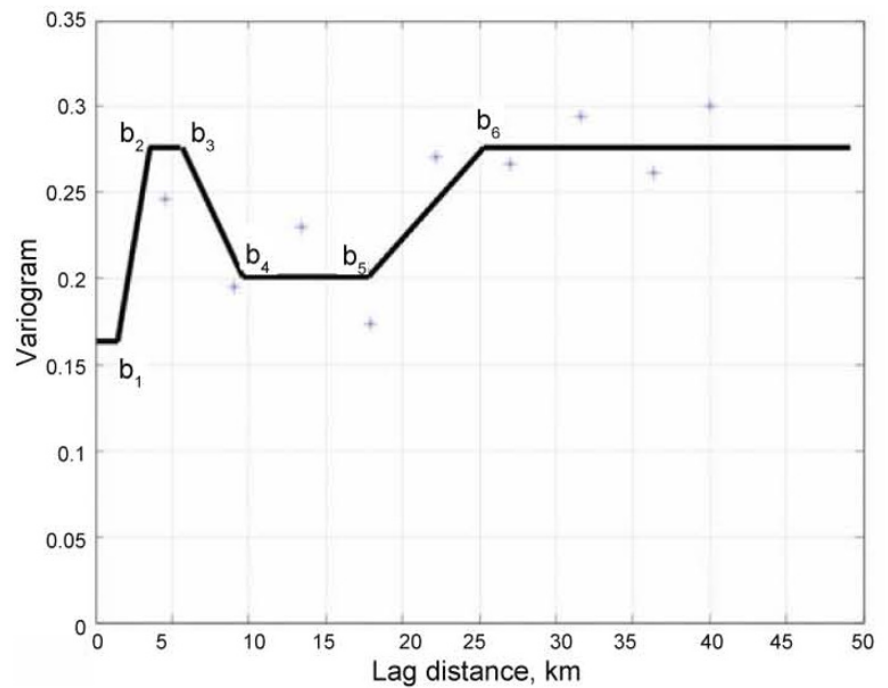

Fig. 7 Experimental indicator variogram of the oil and gas discoveries and fitted step function, showing the spatial characteristics of the discoveries. The valleys in the variogram indicate spatial clustering of the discovered pools at different levels

$b_{1}$ will have no impact on the simulation. The attraction factor $\beta_{2}$, is a parameter for inter-dependencies among field clusters. By setting $b_{2}$ to 0 , it means that no field combination should be beyond a maximum field distance of $b_{4}$. In contrast, if $\quad \beta_{2}$ is set to $1, b_{4}, b_{5}$ and $b_{6}$ will not be effective. From the statistical/geostatistical study of the data, we found that both the inter-dependencies among the fields and the field clusters are weak. Therefore, $\beta_{1}$ and $\beta_{2}$ are set at 0.80 and 0.90 respectively.

Fig. 8 is the probability map derived from hundreds of thousands of equally probable combinations of petroleum accumulations, representing the uncertainty inherited from the data as well as our understanding of the spatial characteristics 


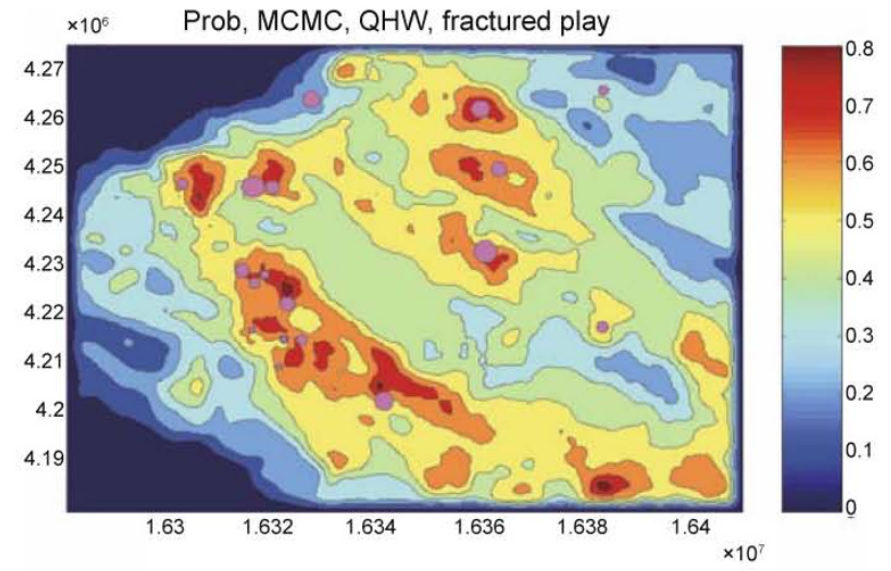

Fig. 8 A probability map of hydrocarbon occurrence derived from the object-based modeling for the fractured play. The geological risk is defined as the chance of petroleum occurrence and as function of space. The higher the probability value of petroleum occurrence is, the lower the geological risk implies. This map provides a consistent basis for prospect ranking and can be used to risk the volumetric calculation in prospect evaluation

of petroleum accumulations in this play. The higher the probability value of a petroleum occurrence is, the lower the geological risk for exploration will be. This map defines the chance of petroleum occurrence for the entire play. If a target exists at a specific location and the average probability value over the target occupancy area represents the probability of geological success, should a subsequent drilling occur. This provides a consistent basis for prospect ranking and can be used to risk the volumetric calculation in prospect evaluation. Examples of the use of this type of probability map for prospect ranking and exploration planning are illustrated by Chen and Osadetz (2006a and 2006b) and Hu et al (2007).

The results of the simulation represent also a refinement to our general understanding with respect to the possible locations of undiscovered petroleum accumulations indicated by the geological favorability map. Compared with the geological favorability map (Fig. 9), the size of the most favorable areas (favorability level ranging from 0.8 to 1.0) shrinks from $17 \%$ (in Fig. 8 ) to $10 \%$ of the simulated probability map (Fig. 9). The best $10 \%$ of the area on Fig. 9 contains 18 discoveries; whereas on Fig. 8, the most favorable $17 \%$ of the area contains only 16 discoveries. By simulation, the model downgrades the areas previously thought most favorable, which are less consistent with other available information, and put these in less favorable categories. Simulated results show that some discoveries are not always located in the areas of the highest predicted probability. This is because target ranking is usually based on a combined consideration of exploration risk and potential rewards. Exploration drilling success rate should be greater in higher probability areas, but not necessarily greater with respect to commercial success. The fact that, in many cases, numerous small prospects remain untested in the areas with high probability suggests that previous exploration has been focused on prospects with moderate risk, but high economic rewards.

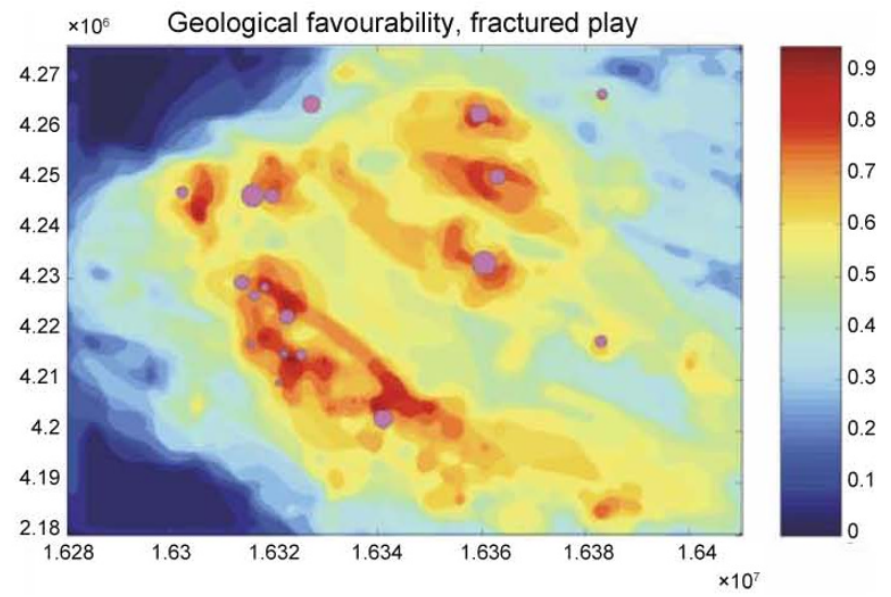

Fig. 9 A geological favorability map of hydrocarbon occurrence derived from a fuzzy method by integrating all essential geological elements for hydrocarbon accumulation in a petroleum system. This map is used as a spatial density function for allocating the undiscovered pools in the objectbased modeling (Hypothesis A)

\section{Conclusions}

The object-based stochastic simulation has the capacity of integrating all available geoscience information and considering spatial correlation, and is a potential tool for geological risk evaluation. The associated uncertainty in predicated pool location represents the geological risk of petroleum occurrence and defines the chance of geological success for the entire study area, providing a consistent basis for prospect ranking. Because this object-based model simultaneously checks the consistencies among models and integrated information, while incorporating spatial correlation, it can update the risk evaluation results from other methods. The object-based stochastic model produces a map indicating the likely locations of petroleum accumulations, which reflects our understanding of the spatial occurrences of petroleum accumulations and is consistent with available information. It provides useful information for strategic decision-making or exploration drilling planning, and sets a consistent basis for prospect ranking in any region of interest.

Compared with pure statistical models (Pan, 1997; Kaufman and Lee, 1992), the results of risk evaluation by this object-based model are better constrained by our general understanding of petroleum geology. The simulated spatial pattern of petroleum occurrences is, in general, more consistent with the geological favorability map. The dependency on the geological favorability map indicates that the reliability of the output is sensitive to the quality of the input favorability map. This could be a drawback, if the quality of geological favorability is not reliable.

\section{Acknowledgements}

The first author thanks Dr. S. Grasby of Geological Survey of Canada for his comments and suggestions on an earlier version of this paper manuscript. This is ESS contribution \#:20080089. 


\section{References}

Arps J J and Roberts T G. Economics of drilling for Cretaceous oil on east flank of Denver-Julesburg Basin. AAPG Bulletin. 1958. 42(11): 2549-2566

Baker R A, Gehman H M, James W R, et al. Geologic field number and size assessments of oil and gas plays. AAPG Bulletin. 1984. 68(4) 426-431

Barton C C and Scholz C H. The fractal size and spatial distribution of hydrocarbon accumulations. In: Fractals in Petroleum Geology and Earth Processes. New York: Plenum Press. 1995. 13-34

Chen Z H, Osadetz K G, Gao H Y, et al. Characterizing the spatial distribution of an undiscovered hydrocarbon resource: the Keg River reef play, Western Canada Sedimentary Basin. Bulletin of Canadian Petroleum Geology. 2000. 48(2): 150-163

Chen Z H, Osadetz K G, Gao H Y, et al. Improving exploration success through uncertainty mapping: the Keg River reef play, Western Canada Sedimentary Basin. Bulletin of Canadian Petroleum Geology. 2001. 49(3): 367-375

Chen Z H, Osadetz K G, Embry A, et al. Geological favorability mapping of petroleum potential using fuzzy integration, example from western Sverdrup Basin, Canadian Arctic Archipelago. Bulletin of Canadian Petroleum Geology. 2002. 50(4): 492-506

Chen Z H, Osadetz K G, Gao H Y, et al. An object-based model for predicting locations of undiscovered oil and gas resources, western Sverdrup Basin, Canada. Marine and Petroleum Geology. 2004. 21(6): 767-777

Chen $\mathrm{Z} \mathrm{H}$ and Osadetz K G. Geological risk mapping and prospect evaluation using multivariate and Bayesian statistical methods, western Sverdrup Basin of Canada. AAPG Bulletin. 2006a. 90(6) 859-872

Chen Z H and Osadetz K G. Undiscovered petroleum accumulation mapping using model-based stochastic simulation. Mathematical Geology. 2006b. 38(1): 1-16

Chen $\mathrm{Z} \mathrm{H}$, Osadetz K G, Hu S, et al. Play resource evaluation and geological risk assessment with model-based simulation. AAPG Convention. San Antonio, Texas, USA. 2008. 20-23

Chen Z H and Sinding-Larsen R. Discovery process modeling-a sensitivity study. Natural Resources Research. 1994. 3(4): 295-303

Davis J C and Chang T. Estimating potential for small fields in mature petroleum province. AAPG Bulletin. 1989. 73(8): 967-976

Gao H Y and Galli A. Hastings-Metropolis algorithm and its convergence properties: open technique report. Centre de Geostatistique. Ecole des Mines de Paris, France. 1998. 41

Gao H Y, Chen Z H, Osadetz K G, et al. A pool-based model of the spatial distribution of undiscovered petroleum resources. Mathematical Geology. 2000. 32(6): 725-749

Hanson A D, Ritts B D, Zinniker D, et al. Upper Oligocene lacustrine source rocks and petroleum systems of the northern Qaidam Basin, Northwest China. AAPG Bulletin. 2001. 85(4): 601-619

Harbaugh J W, Davis J C and Wendebourg J. Computing risk for oil prospects: principles and programs. NewYork: Elsevier Science. 1995. 93-96

Hood K, South B, Walton F D, et al. Use of geographic information systems in hydrocarbon resource assessment and opportunity analysis. In: Geographic Information Systems in Petroleum
Exploration and Development (Edited by Coburn T C and Yarus J M). Tulsa, Oklahoma: American Association of Petroleum Geologists. 2000. 173-185

Hu S Y, Guo Q L, Chen Z H, et al. A method of predicting petroleum resource spatial distribution and its application. Petroleum Exploration and Development. 2007. 34(1): 113-117 (in Chinese)

Hu S Y, Guo Q L, Chen Z H, et al. Application of a multivariateBayesian approach to evaluating geological risk at play level, Nanpu Sag, eastern China. In: Geomathematics and GIS Analysis of Resources (Edited by Zhao P, Agterberg F and Cheng Q). Environment and Hazards, Proceedings of IAMG07. Beijing, 26-31 August, 2007. 641-644

Jin Q, Zha M, Liu Z, et al. Geology and geochemistry of source rocks in the Qaidam Basin, NW China. Journal of Petroleum Geology. 2002: 25(2): 219-238

Kaufman G M, Balcer Y and Kruyt D. A probabilistic model of oil and gas discovery. In: Method of estimating the volume of undiscovered oil and gas resource (Edited by Haunt J D). AAPG Studies in Geology. 1975. (1): 113-142

Kaufman G M and Lee P J. Are wildcat well outcomes dependent or independent? Natural Resources Research. 1992. 1(3): 201-213

La Pointe P R. Estimation of undiscovered hydrocarbon potential through fractal geometry. In: Fractals in Petroleum Geology and Earth Processes (Edited by Barton C C and La Pointe P R). New York: Plenum Press. 1995. 35-57

Lee P J and Wang P C C. Prediction of oil or gas pool sizes when discovery record is available. Mathematical Geology. 1985. 17(2): 95-113

Lee P J, Osadetz K G and Hannigan P. Estimating oil and gas pool-size distributions - examples from the Western Canada Sedimentary Basin. Proceedings of the $5^{\text {th }}$ Annual Conference of the International Association of Mathematical Geology. Trondheim, Norway, 6-11 August, 1999. 439-444

Osadetz G M, Chen Z H and Gao H Y. SuperSD, Version 1.0: A poolbased stochastic simulation program for modeling the spatial distribution of undiscovered petroleum resources. Geological Survey of Canada, Open File \#1465. 2003

Otis R M and Schneidermann N. A process for evaluating exploration prospects. AAPG Bulletin. 1997. 81(7): 1087-1109

Pan G C. Conditional simulation as a tool for measuring uncertainties in petroleum exploration. Natural Resources Research. 1997. 6(4): 285-293

Rose P R. Risk analysis and management of petroleum exploration ventures. AAPG Methods in Exploration. 2001 (12): 27-35

Snow J H, Dore A G and Dorn-Lopez D W. Risk analysis and full-cycle probabilistic modeling of prospect: a prototype system developed for the Norwegian shelf. In: Quantitative prediction and evaluation of petroleum resources (Edited by Dore A G and R Sinding-Larsen). 1997. (6): 135-166

White D A. Oil and gas play maps in exploration and assessment. AAPG Bulletin. 1988. 72(8): 944-949

White D A. Geologic risking guide for prospects and plays. AAPG Bulletin. 1993. 77(12): 2048-2061

Zhao X Z, Chen Z L, Chen H D, et al. Genetic types of tertiary lacustrine algal (cyanobacteria) limestone reservoirs in western Qaidam Basin. Acta Sedimentologica Sinica. 2004. 22(2): 216-224 (in Chinese)

(Edited by Hao Jie) 